\title{
Short-Term Aftereffects of Response Inhibition: Repetition Priming or Between-Trial Control Adjustments?
}

\author{
Frederick Verbruggen \\ Ghent University and Vanderbilt University
}

Gordon D. Logan

Vanderbilt University

\author{
Baptist Liefooghe and André Vandierendonck \\ Ghent University
}

\begin{abstract}
Repetition priming and between-trial control adjustments after successful and unsuccessful response inhibition were studied in the stop-signal paradigm. In 5 experiments, the authors demonstrated that response latencies increased after successful inhibition compared with trials that followed no-signal trials. However, this effect was found only when the stimulus (Experiments 1A-4) or stimulus category (Experiment 3) was repeated. Slightly different results were found after trials on which the response inhibition failed. In Experiments 1A, 2, and 4, response latencies increased after unsuccessful inhibition trials compared with after no-inhibition trials, and this happened whether or not the stimulus repeated. Based on these results, we suggest that the aftereffects of successful response inhibition are primarily due to repetition priming, although there was evidence for between-trial control adjustments when inhibition failed.
\end{abstract}

Keywords: response inhibition, stop-signal paradigm, repetition priming, between-trial control adjustments, executive control

Flexible human behavior calls upon cognitive control and executive processes (Baddeley, 1996; Botvinick, Braver, Barch, Carter, \& Cohen, 2001; Logan, 1985a; Miyake et al., 2000). Within this view, inhibition is often regarded as a key concept of executive control because it refers to "suppression of inappropriate responses, S-R [stimulus-response] mappings or task-sets when the context changes, and suppression of interfering memories during retrieval" (Aron, Robbins, \& Poldrack, 2004, p. 174). In the present study, the focus is on one such function, namely, the inhibition of no-longer required responses. We examined the behavioral consequences of successful and unsuccessful response inhibition and how stop-signal presentation in the stop-signal paradigm (Lappin \& Eriksen, 1966; Logan \& Cowan, 1984; Vince, 1948) influenced subsequent task performance. It has previously been found that response latencies increased after successful inhi-

Frederick Verbruggen, Department of Experimental Psychology, Ghent University and Department of Psychology, Vanderbilt University; Gordon D. Logan, Department of Psychology, Vanderbilt University; Baptist Liefooghe and André Vandierendonck, Department of Experimental Psychology, Ghent University.

Frederick Verbruggen is a postdoctoral fellow of the Research Foundation-Flanders (FWO-Vlaanderen). This research was also supported by National Science Foundation Grant BCS 0446806 to Gordon D. Logan and Air Force Office of Scientific Research Grant FA9550-07-1-0192 to Gordon D. Logan.

We would like to thank Martina Rieger for helpful comments on a previous version of this article.

Correspondence concerning this article should be addressed to Frederick Verbruggen, Department of Psychology, Vanderbilt University, Nashville, TN 37203. E-mail: frederick.verbruggen@ugent.be bition compared with trials that followed no-signal trials (Kramer, Humphrey, Larish, Logan, \& Strayer, 1992; Rieger \& Gauggel, 1999). In five experiments, we evaluated two possible explanations for these aftereffects of response inhibition: between-trial control adjustments and repetition priming.

\section{The Stop-Signal Paradigm}

One of the most frequently used methods for the investigation of response inhibition is the stop-signal paradigm (Lappin \& Eriksen, 1966; Logan \& Cowan, 1984; Vince, 1948). In this paradigm, subjects usually perform a choice reaction task (i.e., the primary task), and on a random selection of the trials, a stop signal instructs subjects to withhold their response. When the stop signal is presented shortly after the primary-task stimulus, subjects can easily withhold their response. As the delay between the primary-task stimulus and the stop signal increases (stop signal delay or SSD), probability of responding typically increases. To account for these observations, Logan and Cowan (1984) proposed the horse race model, which assumes two processes that work against each other: a go process, triggered by the presentation of the primary-task stimulus, and a stop process, triggered by presentation of the stop signal. Response inhibition depends on the relative finishing times of the two processes. If the stop process finishes before the go process, then subjects inhibit their response (signal-inhibit trials). If the go process finishes before the stop process, then response inhibition fails (signal-respond trials).

The horse race model also allows an estimation of the covert latency of the stop process, the stop signal reaction time (SSRT). This measure has proven useful in various settings (for a review, see Logan, 1994). For example, several studies have demonstrated 
that SSRT is elevated in younger children (Williams, Ponesse, Schachar, Logan, \& Tannock, 1999), older adults (Kramer, Humphrey, Larish, Logan, \& Strayer, 1994), impulsive people (Logan, Schachar, \& Tannock, 1997), and in children with attentiondeficit/hyperactivity disorder (ADHD; e.g., Jennings, van der Molen, Pelham, Debski, \& Hoza, 1997; Schachar \& Logan, 1990) compared with corresponding control groups. SSRT is also used to examine the interaction between different inhibitory functions (Ridderinkhof, Band, \& Logan, 1999; Verbruggen, Liefooghe, \& Vandierendonck, 2004, 2006a) or to compare the inhibition of hand and eye movements (Logan \& Irwin, 2000).

In their executive act of control model, Logan and Cowan (1984) suggested that motor control and cognitive control are best viewed as an interaction between an executive system that forms intentions and keeps track of changing goals and a subordinate system that receives the commands and actually performs the required operations. In the stop-signal paradigm, the executive system serves as the mechanism for response inhibition. When a stop signal is presented, the go goal is replaced by the stop goal and the responses are suppressed because support for the underlying processes is cancelled (Logan \& Cowan, 1984). Since this proposal, several authors have endorsed the assumption that executive control processes are involved in the stop-signal paradigm (e.g., Andres, 2003; Chambers et al., 2006; Miyake et al., 2000; Ridderinkhof et al., 1999; Stuphorn \& Schall, 2006; Verbruggen et al., 2004). However, some researchers have argued that control processes also take place after the stop process has already finished.

Kramer, Humphrey, Larish, Logan, and Strayer (1992) were the first to demonstrate that reaction times (RTs) on no-signal trials were longer following a signal-inhibit trial $\left(\mathrm{GO}_{\mathrm{SI}-1}\right)$ than following a no-signal trial $\left(\mathrm{GO}_{\mathrm{NS}-1}\right)$. Rieger and Gauggel (1999) replicated this finding after both signal-inhibit and signal-respond $\left(\mathrm{GO}_{\mathrm{SR}-1}\right)$ trials and postulated that the decision threshold would be higher on trial $n$ when a stop signal was presented on trial $n-1$. In a similar vein, Schachar et al. (2004) reasoned that responding in the presence of a signal would be interpreted by the subject as making an error (see also van Boxtel, van der Molen, \& Jennings, 2005) and used the aftereffect of unsuccessful stopping as a marker for post-error slowing in children with ADHD.

\section{Between-Trial Control Adjustments and Repetition Priming}

Rieger and Gauggel (1999) and Schachar et al. (2004) hypothesized that between-trial control adjustments were made when the stop process was finished. This idea resembles the conflict monitoring theory of Botvinick et al. (Botvinick, Nystrom, Fissell, Carter, \& Cohen, 1999; Botvinick et al., 2001), in which performance in congruency tasks such as the Eriksen flanker task is adjusted after a conflict situation. Botvinick et al. suggested that an evaluation device, the anterior cingulate cortex, detects the conflict and signals for an adjustment in cognitive control via a regulative device, the dorsolateral prefrontal cortex (for similar ideas, see also Milham et al., 2001; Miller \& Cohen, 2001). As a result of these control adjustments, response latencies increase and the conflict between task-relevant and task-irrelevant information decreases (i.e., the so-called conflict-adaptation pattern). This explanation extends beyond performance in conflict tasks, as Botvinick et al. argued that post-error adjustments, as observed by Schachar et al. (2004) and others, could also be explained by the same principles of conflict detection and control adjustment (Botvinick et al., 2001; Botvinick, Cohen, \& Carter, 2004).

The hypothesis that between-trial control adjustments are made after a signal trial was also recently proposed by Emeric et al. (2007). These authors found that saccade latencies in a countermanding task were longer for trials that followed an inhibited saccadic response than for trials that followed a saccadic response (see also Cabel, Armstrong, Reingold, \& Munoz, 2000). Based on these results, Emeric et al. (2007) suggested that the conflict monitoring theory of Botvinick et al. (2001) could account for this data pattern, on the assumption that there is conflict between the stop process and the go process on stop-signal trials. Rieger and Gauggel (1999) also hypothesized that control settings were adjusted after the stop-signal presentation, although they did not attribute this to a conflict between processes.

While between-trial control adjustments are a plausible explanation for the aftereffects of successful and unsuccessful response inhibition, other explanations are possible. First, an increase in response threshold should produce not only a lengthening of RT but also a concomitant reduction in error rate (Rabbitt, 1966). However, Schachar et al. (2004) did not observe such a reduction in error rate (Rieger \& Gauggel, 1999, did not report error rates for the different types of trials). Therefore, the failure to confirm this error-reduction prediction motivates a search for other mechanisms that can contribute to post-stop-signal slowing. Second, Rieger and Gaugel (1999) also analyzed stimulus-repetition effects and found that the aftereffects of response inhibition were stronger when the stimulus from trial $n-1$ was repeated. Based on this finding, Rieger and Gauggel (1999; see also Logan, 1994) suggested that repetition-priming effects, such as negative priming (for a review, see May, Kane, \& Hasher, 1995), could contribute to the aftereffects of response inhibition. In a previous study (Verbruggen, Liefooghe, \& Vandierendonck, 2005), we tested this hypothesis by introducing stop signals in a negative-priming paradigm. However, contrary to Rieger and Gauggel (1999), we did not find that $\mathrm{GO}_{\mathrm{SI}-1} \mathrm{RT}$ were longer than $\mathrm{GO}_{\mathrm{NS}-1}$ RTs. ${ }^{1}$ Instead, we found evidence of post-error slowing after signal-respond trials. Thus, our results demonstrated that between-trial control adjustments are not always made after a stop-signal trial.

Third, several studies recently pointed out that sequential effects do not necessarily indicate behavioral control adjustments (see Mayr, Awh, \& Laurey, 2003; Nieuwenhuis et al., 2006). For example, Mayr et al. argued that the conflict-adaptation pattern was confounded with stimulus-response repetitions and that it was merely a consequence of the retrieval of processing episodes or

\footnotetext{
${ }^{1}$ In our previous study (Verbruggen, Liefooghe, \& Vandierendonck, 2005), we did not find prolonged RTs after successfully stopped trials. However, we did find an effect of response inhibition on the negative priming effect. The negative priming effect in congruency tasks refers to the finding that RTs increase when the distracter from trial $n-1$ becomes the target of trial $n$, compared with trials on which the target and distracter from trial $n$ were not presented on trial $n-1$. Interestingly, we found that in the standard stop-signal paradigm, the negative priming effect was absent after a signal-inhibit trial, whereas a significant negative priming effect was observed after a signal-respond or a no-signal trial (Verbruggen et al., 2005).
} 
instances (Logan, 1988, 1990). Mayr et al. (2003) suggested that retrieval of previous processing episodes could account for the conflict-adaptation pattern without the involvement of extra control processes. However, some studies could still find evidence for between-trial control adjustments in congruency tasks when different kinds of repetitions are excluded (e.g., Kerns et al., 2004; Verbruggen, Notebaert, Liefooghe, \& Vandierendonck, 2006), suggesting that both repetition priming and between-trial control adjustments contribute to sequential effects.

\section{The Present Study}

In the present study, we investigated between-trial control adjustments and repetition priming in the stop-signal paradigm. So far, the results are mixed, and it remains unclear which processes contribute to the aftereffects of response inhibition. We distinguished between two hypotheses. The between-trial control adjustment hypothesis assumes that subjects adjust control settings after successful response inhibition, unsuccessful response inhibition, or both (Emeric et al., 2007; Rieger \& Gauggel, 1999). The repetition-priming hypothesis assumes that aftereffects of successful and unsuccessful response inhibition are primarily due to repetition priming. Based on the instance theory of automatization (Logan, 1988), it is assumed that a processing episode is stored after each trial. Such an episode consists of a specific combination of the stimulus, the interpretation given to the stimulus, the associated response, and the task goal, and is retrieved when the stimulus is repeated. Consequently, when the stimulus of the previous stop trial is repeated, the stop goal of trial $n-1$ is activated, and this suppresses the go response (Logan \& Cowan, 1984).

To test both hypotheses, we focused on the relative contribution of between-trial control adjustments and repetition priming in Experiments $1 \mathrm{~A}$ and $1 \mathrm{~B}$, using designs that closely resembled those of Verbruggen et al. (2005; Experiment 1A of the present study) and of Rieger and Gauggel (1999; Experiment 1B of the present study). By doing so, we hoped to establish the basic effects to be examined in subsequent experiments.

In Experiments 2 and 3, we focused primarily on the repetitionpriming effects found by Rieger and Gauggel (1999). In both experiments, we used the information-reduction procedure (Bertelson, 1965), in which four stimuli are mapped on two responses. In Experiment 2, the stimuli were noncategorizable (namely four shapes that were arbitrarily mapped on two responses), and the information-reduction procedure resulted in three types of trials: stimulus-repetition trials, on which both the stimulus and the response of trial $n-1$ are repeated; response-repetition trials, on which only the response of trial $n-1$ is repeated; and no-repetition trials, on which both the response and the stimulus of trial $n-1$ change. In Experiment 3, the stimuli (digits and letters) were categorically mapped on the responses (e.g., digits = left and letters $=$ right). This manipulation resulted in three trial types: stimulus-repetition trials, on which the stimulus and stimulus category of trial $n-1$ are repeated; category-repetition trials, on which only the stimulus category of trial $n-1$ is repeated; and no-repetition trials, on which the stimulus category changes. Note that category repetitions are also response repetitions, but as we argue later, both trial types typically lead to a different pattern of results. By examining aftereffects of stopping in each of these trial types in Experiments 2 and 3, we could determine whether repetition priming effects were stimulus related, response related, or both. Finally, in Experiment 4, we used a variant of the standard stop-signal task, the selective stop-signal task (Bedard et al., 2002; Logan, Kantowitz, \& Riegler, 1986) to investigate the effect of the presentation of the stop signal itself.

In all experiments, the predictions were as follows. If betweentrial control adjustments are made after signal-inhibit trials, then we should find longer $\mathrm{GO}_{\mathrm{SI}-1}$ RTs compared with $\mathrm{GO}_{\mathrm{NS}-1} \mathrm{RTs}$, and this should occur whether or not the stimulus from trial $n-1$ is repeated. According to the between-trial control adjustment hypothesis, adjustments are made after stop-signal presentation on trial $n-1$ and before stimulus presentation on trial $n$. Consequently, between-trial control adjustments should be observed for both stimulus-repetition and no-repetition trials. On the other hand, if the aftereffect of successful response inhibition is due primarily to repetition priming, then $\mathrm{GO}_{\mathrm{SI}-1} \mathrm{RTs}$ should be longer than $\mathrm{GO}_{\mathrm{NS}-1} \mathrm{RTs}$ only for stimulus-repetition trials (for a similar reasoning, see Mayr et al., 2003). Similarly, we investigated the relative contribution of between-trial control adjustments and repetition-priming effects after unsuccessful response inhibition by contrasting $\mathrm{GO}_{\mathrm{SR}-1}$ with $\mathrm{GO}_{\mathrm{NS}-1}$ trials.

\section{Experiment $1 \mathrm{~A}$}

In Experiments 1A and 1B, we expected to establish the basic pattern effects of between-trial control adjustments and repetition priming. In a previous study (Verbruggen et al., 2005), we tried to tackle this issue by focusing on the relation between the negative priming effect observed in congruency tasks such as the Stroop task (Dalrymple-Alford \& Budayr, 1966) and the aftereffects observed in the stop-signal paradigm. However, the results were inconclusive because we did not observe direct aftereffects of response inhibition. Several factors might have contributed to the absence of aftereffects of response inhibition. First, in line with most negative priming studies, we presented trials in pairs, with a short intertrial interval (ITI) between trials of the same pair and a longer ITI between trials of a different pair. In addition, we presented only one stop signal within one pair. In combination with the ITI differences, it was very likely that subjects were aware of this restriction, and this might have influenced between-trial control adjustments. Second, the target stimulus of the first trial of a pair was never repeated on the second trial of a pair. Because negative priming was manipulated within trial pairs, we analyzed only the second trial of a pair. Therefore, immediate stimulus repetitions were not included in the analyses. Consequently, our previous study did not allow us to make strong statements about the relation between target-related repetition-priming effects and between-trial control adjustments after the inhibition of a response.

To distinguish between control adjustments and repetition priming after both successful and unsuccessful stopping, we allowed stimulus repetitions to occur on all trials in Experiments $1 \mathrm{~A}$ and 1B. In Experiment 1A, trials were presented in pairs, but there was no longer a restriction on the number of stop signals within one pair of trials. Stop signals could occur on the first or second trial of a pair, on both trials, or on neither trial. The design of Experiment 1B was similar to the design of Rieger and Gauggel (1999), with a constant ITI between all trials. Trials were not presented in pairs. 


\section{Method}

Subjects. Ten students at Ghent University participated in exchange for a payment of $€ 10$ for $1 \mathrm{hr}$. All subjects had normal or corrected-to-normal vision, and all were naive as to the purpose of the experiment. Subjects were tested in groups of 3 or less.

Apparatus and stimuli. The experiment was run on a Pentium 4 PC equipped with Tscope (Stevens, Lammertyn, Verbruggen, \& Vandierendonck, 2006), and the stimuli were presented on a 17-in. $(43.2-\mathrm{cm})$ monitor. For half of the subjects, the primary task was to respond with the left hand to a circle (diameter: $1 \mathrm{~cm}$ ) and the right hand to a square $(1 \times 1 \mathrm{~cm})$. For the other half of the subjects, the mapping rule was reversed. Subjects responded by pressing the $V$ or the $N$ key of a QWERTY keyboard with the index fingers of the left and right hand, respectively. The fixation sign $(+)$ and stimuli were presented in white on a black background. Occasionally, a loud, clear auditory stop signal $(750 \mathrm{~Hz}$, $60 \mathrm{~dB}, 75 \mathrm{~ms}$ ) was presented through closed headphones (Sennheiser HD 265-1) shortly after the stimulus onset in the primary task.

Procedure. Subjects received oral instructions, emphasizing both accuracy and speed. The trials were presented in pairs (see Figure 1). Each pair of trials began with the presentation of the fixation sign in the center of the screen, which was replaced after $250 \mathrm{~ms}$ by the first stimulus. The stimulus remained on the screen until subjects responded, or until 1,500 ms had elapsed. The ITI between the first and the second trial of a pair was $350 \mathrm{~ms}$. The second trial of a pair also began with the presentation of the fixation sign, which was replaced after $250 \mathrm{~ms}$ by a second stimulus. The ITI started after the response to the second stimulus

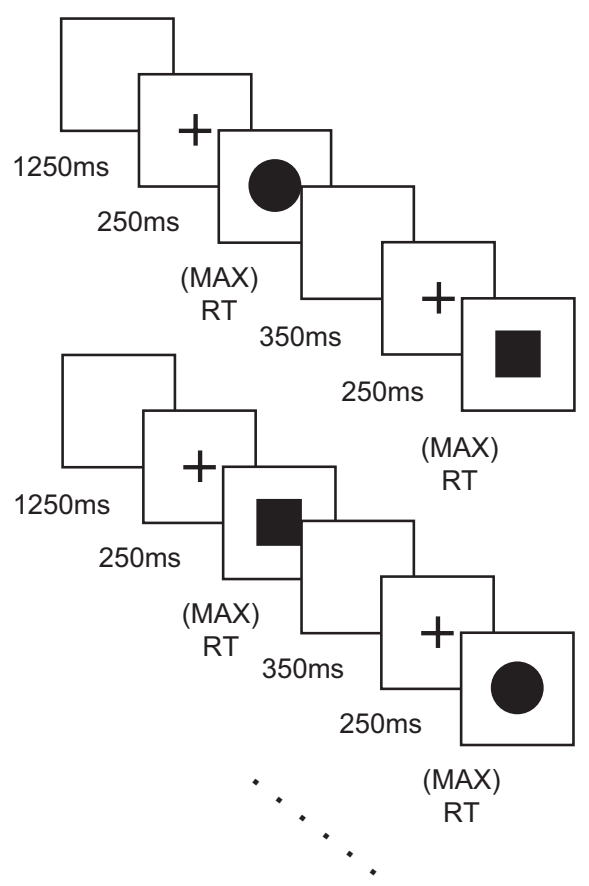

Figure 1. An example of two pairs of trials with a longer intertrial interval between pairs than within pairs. The stimulus remained on the screen until the subjects responded (reaction time, RT) or until the maximal reaction time (MAX RT) had elapsed. or after 1,500 ms had elapsed. The ITI between pairs was 1,250 ms.

On $25 \%$ of the trials, a stop signal was presented. Stop signals could occur on both trials of the pair without further restrictions. The SSD was initially set at $250 \mathrm{~ms}$ and continuously adjusted according to a tracking procedure to obtain a stopping probability of .50. Each time a subject responded to the stimulus in the presence of a stop signal, SSD decreased by $25 \mathrm{~ms}$. When inhibition succeeded, SSD increased by $25 \mathrm{~ms}$. Based on the assumptions of the horse-race model, SSRT can be calculated by subtracting mean SSD from the untrimmed mean RT (Logan \& Cowan, 1984; Logan et al., 1997). In line with previous studies (Logan et al., 1997; Rieger \& Gauggel, 1999; Verbruggen et al., 2004, 2005), subjects were informed about the tracking procedure and were told not to let the stop task interfere with the primary task and not to wait for the stop signal. Furthermore, they were told that on some trials it would be easy to stop and on other trials it would be more difficult or even impossible to stop because the stop signal would be presented near response execution.

The experiment started with one practice block of 32 trials. During the practice phase, subjects could receive immediate feedback on each trial of the pair. When subjects made an error on a no-signal trial, the word fout (meaning wrong) appeared. If they did not respond in time, the sentence "tracht sneller te reageren" (meaning "try to respond faster") was presented. When subjects responded in the presence of a stop signal, the sentence "tracht te stoppen" (meaning "try to stop") appeared. The feedback remained in the center of the screen for $750 \mathrm{~ms}$, after which the ITI started. The experimental phase consisted of 15 blocks of 64 trials, during which no immediate feedback was presented. At the end of each block, the number of errors made during the block, the mean RT, and the probability of stopping were displayed, and subjects had to pause for $15 \mathrm{~s}$. The experimenter could follow online and urge the subjects to make fewer errors when accuracy on no-signal trials was too low $(<90 \%)$ or to respond faster when mean RT was artificially high $(>1,000 \mathrm{~ms})$.

\section{Results and Discussion}

Mean SSRT, calculated as described above, was $165 \mathrm{~ms}$, with a mean probability of responding of .494 and a mean SSD of 323 ms. Mean RTs of correct no-signal trials were calculated after removal of errors and trials following no-signal errors. Outlying RTs (i.e., RTs longer than 2.5 standard deviations above the mean for each trial type) were discarded from data analysis. This trimming procedure resulted in a data reduction of $3.1 \%$. Subjects made very few errors $(2.8 \%)$, and there were no indications of a speed-accuracy trade-off, so analyses focused only on RTs.

Of the included trials, $50.2 \%$ were no-repetition trials. The relevant means appear in Table 1 . In the initial analyses, we analyzed the first trial and second trial of a pair separately. In general, we found that no-signal RTs were shorter for the first trial of a pair (480 ms) compared with the second trial of a pair (520 $\mathrm{ms})$. However, the aftereffects of stopping were similar for both trials of a pair. As can be seen in Table 1, we found the same interaction between signal properties of trial $n-1$ and repetitionalthough this interaction was more pronounced for the second trial of the pair, as indicated by the significant three-way interaction, $F(2,18)=4.7, M S E=1,238, p<.05$. Given the similarities and 
Table 1

Reaction Times (RT; in Milliseconds) and Error Rates for Three Trial Types in Experiments 1A-4

\begin{tabular}{|c|c|c|c|c|c|c|}
\hline & \multicolumn{2}{|c|}{ No repetition } & \multicolumn{2}{|c|}{$\begin{array}{l}\text { Response repetition or } \\
\text { category repetition }\end{array}$} & \multicolumn{2}{|c|}{ Stimulus repetition } \\
\hline & $\mathrm{RT}$ & Error \% & RT & Error \% & RT & Error \% \\
\hline \multicolumn{7}{|c|}{ Experiment 1A: T1 } \\
\hline $\mathrm{GO}_{\mathrm{NS}-1}$ & 464 (19) & $4.0(1.5)$ & & & $448(16)$ & $3.4(1.4)$ \\
\hline $\mathrm{GO}_{\mathrm{SR}-1}$ & $494(26)$ & $2.5(1.4)$ & & & $514(21)$ & $2.1(0.9)$ \\
\hline $\mathrm{GO}_{\mathrm{SI}-1}$ & $470(20)$ & $2.9(2.6)$ & & & $493(26)$ & $5.6(3.1)$ \\
\hline \multicolumn{7}{|c|}{ Experiment 1A: T2 } \\
\hline $\mathrm{GO}_{\mathrm{NS}-1}$ & $492(19)$ & $3.5(1.4)$ & & & 449 (16) & $2.2(1.2)$ \\
\hline $\mathrm{GO}_{\mathrm{SR}-1}$ & $572(29)$ & $2.3(1.8)$ & & & $558(21)$ & $4.0(1.6)$ \\
\hline $\mathrm{GO}_{\mathrm{SI}-1}$ & $485(16)$ & $3.0(2.3)$ & & & $563(32)$ & $1.9(1.3)$ \\
\hline \multicolumn{7}{|c|}{ Experiment 1B } \\
\hline $\mathrm{GO}_{\mathrm{NS}-1}$ & $507(31)$ & $1.7(0.8)$ & & & $481(36)$ & $1.2(0.6)$ \\
\hline $\mathrm{GO}_{\mathrm{SR}-1}$ & $498(34)$ & $0.0(0.0)$ & & & $520(35)$ & $0.5(0.5)$ \\
\hline $\mathrm{GO}_{\mathrm{SL}-1}$ & $513(43)$ & $1.4(0.7)$ & & & $533(36)$ & $1.1(1.1)$ \\
\hline \multicolumn{7}{|c|}{ Experiment 2} \\
\hline $\mathrm{GO}_{\mathrm{NS}-1}$ & $562(14)$ & $3.1(0.6)$ & $572(19)$ & $7.1(1.4)$ & $502(15)$ & $1.1(0.3)$ \\
\hline $\mathrm{GO}_{\mathrm{SR}-1}$ & $587(16)$ & $3.2(0.8)$ & $613(23)$ & $6.1(2.2)$ & $548(19)$ & $1.2(0.7)$ \\
\hline $\mathrm{GO}_{\mathrm{SI}-1}$ & $569(17)$ & $2.1(1.0)$ & $584(19)$ & $3.1(1.2)$ & $591(20)$ & $2.6(1.2)$ \\
\hline \multicolumn{7}{|c|}{ Experiment 3} \\
\hline $\mathrm{GO}_{\mathrm{NS}-1}$ & $510(25)$ & $2.3(0.5)$ & $486(23)$ & $4.1(0.9)$ & $458(22)$ & $0.9(0.3)$ \\
\hline $\mathrm{GO}_{\mathrm{SR}-1}$ & $514(23)$ & $1.4(0.9)$ & $543(28)$ & $5.3(1.6)$ & $511(30)$ & $0.0(0.0)$ \\
\hline $\mathrm{GO}_{\mathrm{SI}-1}$ & $514(26)$ & $1.4(0.5)$ & $536(29)$ & $1.0(0.7)$ & $529(30)$ & $2.4(0.9)$ \\
\hline \multicolumn{7}{|c|}{ Experiment 4} \\
\hline $\mathrm{GO}_{\mathrm{NS}-1}$ & $455(9)$ & $1.8(0.4)$ & & & $434(7)$ & $2.2(0.5)$ \\
\hline $\mathrm{GO}_{\mathrm{SR}-1}$ & 477 (17) & $1.2(0.6)$ & & & $511(21)$ & $2.1(0.8)$ \\
\hline $\mathrm{GO}_{\mathrm{SI}-1}$ & 449 (14) & $0.8(0.6)$ & & & $491(13)$ & $1.6(0.8)$ \\
\hline $\mathrm{GO}_{\mathrm{IV}-1}$ & 457 (12) & $1.1(0.4)$ & & & $459(9)$ & $2.4(0.8)$ \\
\hline
\end{tabular}

Note. Standard errors are in parentheses. $\mathrm{GO}_{\mathrm{NS}-1}$ : trial $n-1=$ no-signal trial; $\mathrm{GO}_{\mathrm{SR}-1}$ : trial $n-1=$ signal-respond trial; $\mathrm{GO}_{\mathrm{SI}-1}$ : trial $n-1=$ signal-inhibit trial; $\mathrm{GO}_{\mathrm{IV}-1}$ : trial $n-1=$ invalid-signal trial (Experiment 4). For Experiment $1 \mathrm{~A}$ : $\mathrm{T} 1=$ the first trial of a pair, T2 $=$ the second trial of a pair. Besides stimulus-repetition and no-repetition trials, there were also response-repetition trials in Experiment 2 and category-repetition trials in Experiment 3.

to avoid redundancy, we collapsed the data across both trials in a pair in all subsequent analyses. RTs of no-signal trials were ana-

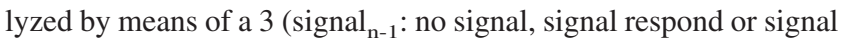
inhibit) $\times 2$ (repetition: stimulus repetition or no repetition) repeated measures analysis of variance (ANOVA). The collapsed mean RTs are depicted in Figure 2. The global ANOVAs are reported in Table 2.

As can be seen, the ANOVA yielded a main effect of signal ${ }_{n-1}$, but no effect of repetition. More important, in line with the findings of Rieger and Gauggel (1999), we found an interaction between signal ${ }_{n-1}$ and repetition. Therefore, we conducted planned comparisons using the error term of the interaction from the omnibus ANOVA. The planned comparisons of interest are reported in Table 3. First, we focused on the effects observed after successful response inhibition and compared $\mathrm{GO}_{\mathrm{SI}-1}$ RTs with $\mathrm{GO}_{\mathrm{NS}-1}$ RTs. When the stimulus was repeated, $\mathrm{GO}_{\mathrm{SI}-1}$ RTs (527 $\mathrm{ms}$ ) were longer than $\mathrm{GO}_{\mathrm{NS}-1} \mathrm{RTs}(448 \mathrm{~ms})$. However, for norepetition trials, there was no difference between $\mathrm{GO}_{\mathrm{SI}-1}$ RTs (478 $\mathrm{ms})$ and $\mathrm{GO}_{\mathrm{NS}-1} \mathrm{RTs}(478 \mathrm{~ms})$. These results are therefore only a partial replication of the findings of Rieger and Gauggel (1999), who found that $\mathrm{GO}_{\mathrm{SI}-1}$ RTs were longer than $\mathrm{GO}_{\mathrm{NS}-1}$ RTs for both stimulus-repetition and no-repetition trials. The fact that the aftereffects of successful response inhibition depended on repetition of the primary task stimulus argues against an explanation in terms of between-trial control adjustments. On the one hand, between- control adjustments should result in longer $\mathrm{GO}_{\mathrm{SI}}$ RTs compared with $\mathrm{GO}_{\mathrm{NS}}$ RTs on both no-repetition and stimulus-repetition trials. On the other hand, the results of Experiment 1A are in line with the repetition-priming hypothesis, which postulates that the aftereffects of successful response inhibition depend on the repetition of the primary task stimulus.

Second, we analyzed whether between-trial control adjustments were made after unsuccessful response inhibition. When the stimulus was repeated, we observed that $\mathrm{GO}_{\mathrm{SR}-1} \mathrm{RTs}(536 \mathrm{~ms})$ were longer than $\mathrm{GO}_{\mathrm{NS}-1}$ RTs $(448 \mathrm{~ms})$. A similar pattern of results was observed for no-repetition trials, with $\mathrm{GO}_{\mathrm{SR}-1} \mathrm{RTs}(533 \mathrm{~ms})$ being longer than $\mathrm{GO}_{\mathrm{NS}-1} \mathrm{RTs}(478 \mathrm{~ms})$. These findings indicate that post-error adjustments are made after signal-respond trials (Schachar et al., 2004; Verbruggen et al., 2005).

\section{Experiment 1B}

In contrast to Experiment $1 \mathrm{~A}$, we no longer presented trials in pairs in Experiment 1B. Thus, the design of Experiment 1B was similar to that of Rieger and Gauggel (1999), with a constant ITI between all trials.

\section{Method}

Subjects. Subjects were drawn from the same pool (with exclusion of subjects who participated in Experiment 1A) and met 

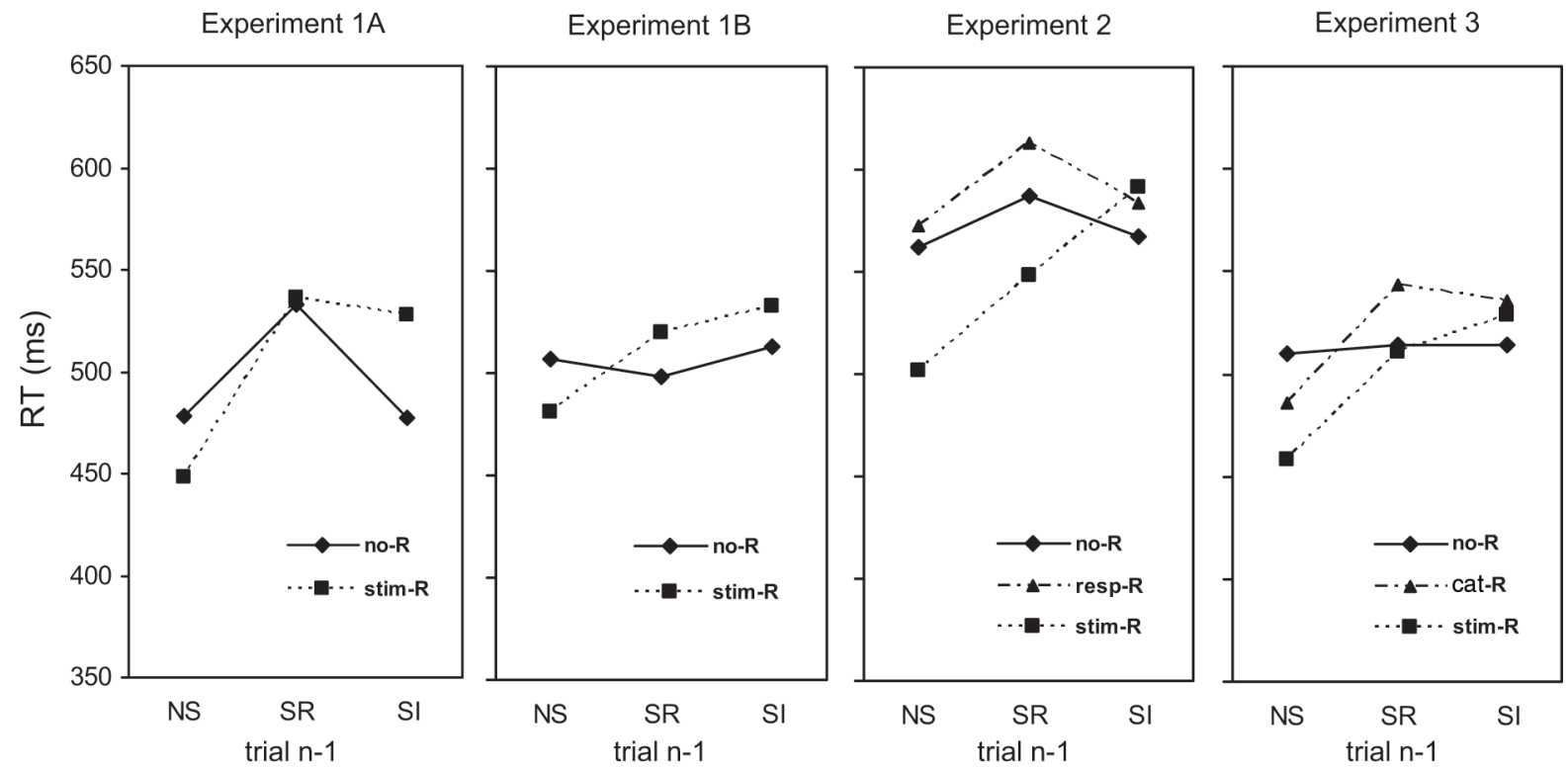

Figure 2. Reaction time (RT) of no-signal trials in Experiments 1A-3. RTs of no-repetition (no-R), stimulusrepetition (stim-R), response-repetition (resp-R; Experiment 2), and category-repetition (cat-R; Experiment 3 ) trials presented as a function of the signal properties of trial $n-1$ (no signal [NS], signal respond [SR], signal inhibit[SI]).

the same criteria as in Experiment 1A. Eight subjects participated in exchange for a payment of $€ 5$ for $30 \mathrm{~min}$.

Apparatus, stimuli, and procedure. Apparatus and stimuli were identical to those used in Experiment 1A. Presentation duration of the fixation sign was $500 \mathrm{~ms}$, and the ITI was always 1,000 ms. The experimental phase consisted of eight blocks of 64 trials. There were no other differences with respect to Experiment 1A.

Table 2

Summary Tables for Analyses of Variance Performed on Mean Reaction Times

\begin{tabular}{|c|c|c|c|c|}
\hline Experiment and variable & $d f$ & $M S E$ & $F$ & $\eta_{p}^{2}$ \\
\hline \multicolumn{5}{|l|}{ Experiment $1 \mathrm{~A}$} \\
\hline Repetition (R) & 1,9 & 874 & 1.0 & .10 \\
\hline Signal $_{n-1}(\mathrm{~S})$ & 2,18 & 970 & $26.3^{* *}$ & .75 \\
\hline $\mathrm{S} \times \mathrm{R}$ & 2,18 & 1,203 & $6.6^{* *}$ & .42 \\
\hline \multicolumn{5}{|l|}{ Experiment $1 \mathrm{~B}$} \\
\hline Repetition & 1,7 & 520 & 0.7 & .10 \\
\hline Signal $_{n-1}$ & 2,14 & 596 & $5.6^{*}$ & .45 \\
\hline $\mathrm{S} \times \mathrm{R}$ & 2,14 & 579 & $5.1^{*}$ & .42 \\
\hline \multicolumn{5}{|l|}{ Experiment 2} \\
\hline Repetition & 2,30 & 2,210 & $10.0^{* * *}$ & .40 \\
\hline Signal $_{n-1}$ & 2,30 & 1,511 & $14.3^{* *}$ & .49 \\
\hline $\mathrm{S} \times \mathrm{R}$ & 4,60 & 717 & $14.3^{* *}$ & .49 \\
\hline \multicolumn{5}{|l|}{ Experiment 3} \\
\hline Repetition & 2,20 & 820 & $5.2^{*}$ & .35 \\
\hline Signal $_{n-1}$ & 2,20 & 1,335 & $13.1^{* *}$ & .57 \\
\hline $\mathrm{S} \times \mathrm{R}$ & 4,40 & 422 & $9.8^{* * *}$ & .50 \\
\hline \multicolumn{5}{|l|}{ Experiment 4} \\
\hline Repetition & 1,15 & 1,334 & $4.9^{*}$ & .25 \\
\hline Signal $_{n-1}$ & 3,45 & 1,385 & $10.1^{* * *}$ & .40 \\
\hline $\mathrm{S} \times \mathrm{R}$ & 3,45 & 783 & $8.5^{*}$ & .36 \\
\hline
\end{tabular}

${ }^{*} p<.05 . \quad{ }^{* *} p<.01$.

\section{Results and Discussion}

Mean SSRT was $159 \mathrm{~ms}$, with a mean probability of responding of .49 and a mean SSD of $350 \mathrm{~ms}$. The data trimming procedure resulted in a data reduction of $2.6 \%$. Subjects made few errors $(1.0 \%)$, and there were no indications of a speedaccuracy trade-off, so analyses focused only on RTs. Of the trials included in the analysis, $49.9 \%$ were no-repetition trials. Mean RTs and error percentages appear in Table 1. RTs of no-signal trials were analyzed by means of a 3 (signal $_{n-1}$ : no signal, signal respond, or signal inhibit) $\times 2$ (repetition: stimulus repetition or no repetition) repeated measures ANOVA. The global ANOVAs are reported in Table 2, and the planned comparisons of interest are reported in Table 3.

As can be seen in Table 2, we found a main effect of signal $_{n-1}$, but no effect of repetition. The interaction between signal $_{n-1}$ and repetition did reach significance and is depicted in Figure 2. When the stimulus was repeated, we found that $\mathrm{GO}_{\mathrm{NS}-1}$ RTs (481 ms) were shorter than $\mathrm{GO}_{\mathrm{SR}-1}$ RTs (558 ms) and $\mathrm{GO}_{\mathrm{SI}-1}$ RTs $(563 \mathrm{~ms})$. For no-repetition trials, $\mathrm{GO}_{\mathrm{NS}-1} \mathrm{RTs}$ (507 ms) were comparable to $\mathrm{GO}_{\mathrm{SR}-1} \mathrm{RTs}(498 \mathrm{~ms})$ and $\mathrm{GO}_{\mathrm{SI}-1}$ RTs $(513 \mathrm{~ms})$. In line with Experiment 1A, the findings of Experiment 1B also argue against the between-trial control adjustment hypothesis for the aftereffects of successful response inhibition because we did not find an effect of signal $_{n-1}$ on no-repetition trials. However, the different effect of signal $_{n-1}$ on stimulus-repetition and no-repetition trials is consistent with the repetition-priming hypothesis. Contrary to the results of Experiment 1A, we did not find any evidence for post-error slowing after a signal-respond trial. We return to this point in the General Discussion. 
Table 3

Planned Comparisons of Interest on Mean Reaction Times

\begin{tabular}{|c|c|c|c|c|c|c|}
\hline & \multicolumn{2}{|c|}{$\begin{array}{l}\text { No } \\
\text { repetition }\end{array}$} & \multicolumn{2}{|c|}{$\begin{array}{l}\text { Response or } \\
\text { category } \\
\text { repetition }\end{array}$} & \multicolumn{2}{|c|}{$\begin{array}{l}\text { Stimulus } \\
\text { repetition }\end{array}$} \\
\hline & $F$ & $\eta_{p}^{2}$ & $F$ & $\eta_{p}^{2}$ & $F$ & $\eta_{p}^{2}$ \\
\hline \multicolumn{7}{|c|}{ Experiment $1 \mathrm{~A}(d f=1,18)$} \\
\hline $\mathrm{GO}_{\mathrm{NS}-1}$ vs. $\mathrm{GO} 1_{\mathrm{SR}-1}$ & $12.5^{* * *}$ & .41 & & & $31.9^{* *}$ & .85 \\
\hline $\mathrm{GO}_{\mathrm{NS}-1}$ vs. $\mathrm{GO}_{\mathrm{SI}-1}$ & 0.0 & .00 & & & $25.9^{* *}$ & .64 \\
\hline \multicolumn{7}{|c|}{ Experiment $1 \mathrm{~B}(d f=1,14)$} \\
\hline $\mathrm{GO}_{\mathrm{NS}-1}$ vs. $\mathrm{GO} 1_{\mathrm{SR}-1}$ & 0.6 & .04 & & & $10.5^{* *}$ & .68 \\
\hline $\mathrm{GO}_{\mathrm{NS}-1}$ vs. $\mathrm{GO}_{\mathrm{SI}-1}$ & 0.3 & .02 & & & $18.5^{* *}$ & .72 \\
\hline \multicolumn{7}{|c|}{ Experiment $2(d f=1,60)$} \\
\hline $\mathrm{GO}_{\mathrm{NS}-1}$ vs. GO1 $1_{\mathrm{SR}-1}$ & $7.1^{* * *}$ & .11 & $19.4^{* * *}$ & .41 & $24.1^{* *}$ & .57 \\
\hline $\mathrm{GO}_{\mathrm{NS}-1}$ vs. $\mathrm{GO}_{\mathrm{SI}-1}$ & 0.3 & .00 & 1.8 & .14 & $89.1^{* *}$ & .72 \\
\hline \multicolumn{7}{|c|}{ Experiment $3(d f=1,40)$} \\
\hline $\mathrm{GO}_{\mathrm{NS}-1}$ vs. $\mathrm{GO} 1_{\mathrm{SR}-1}$ & 0.2 & .00 & $42.0^{* * *}$ & .67 & $36.8^{* *}$ & .70 \\
\hline $\mathrm{GO}_{\mathrm{NS}-1}$ vs. $\mathrm{GO}_{\mathrm{SI}-1}$ & 0.2 & .00 & $32.4^{* *}$ & .66 & $67.0^{* *}$ & .75 \\
\hline \multicolumn{7}{|c|}{ Experiment $4(d f=1,45)$} \\
\hline $\mathrm{GO}_{\mathrm{NS}-1}$ vs. $\mathrm{GO}_{\mathrm{SR}-1}$ & $4.7^{*}$ & .10 & & & $60.1^{*}$ & .59 \\
\hline $\mathrm{GO}_{\mathrm{NS}-1}$ vs. $\mathrm{GO}_{\mathrm{SI}-1}$ & 0.3 & .01 & & & $32.8^{* *}$ & .69 \\
\hline $\mathrm{GO}_{\mathrm{NS}-1}$ vs. $\mathrm{GO} 1_{\mathrm{IV}-1}$ & 0.0 & .00 & & & $6.6^{*}$ & .64 \\
\hline $\mathrm{GO}_{\mathrm{IV}-1}$ vs. $\mathrm{GO} 1_{\mathrm{SR}-1}$ & $4.1^{*}$ & .08 & & & $27.0^{* *}$ & .40 \\
\hline $\mathrm{GO}_{\mathrm{IV}-1}$ vs. $\mathrm{GO} 1_{\mathrm{SI}-1}$ & 0.5 & .01 & & & $27.0^{* *}$ & .34 \\
\hline
\end{tabular}

Note. $\mathrm{GO}_{\mathrm{NS}-1}$ : trial $n-1=$ no-signal trial; $\mathrm{GO}_{\mathrm{SR}-1}$ : trial $n-1=$ signal-respond trial; $\mathrm{GO}_{\mathrm{SI}-1}$ : trial $n-1=$ signal-inhibit trial; $\mathrm{GO}_{\mathrm{IV}-1}$ : trial $n-1=$ invalid-signal trial (Experiment 4). Besides stimulus-repetition and no-repetition trials, there were also response-repetition trials in Experiment 2 and category-repetition trials in Experiment 3. Fs were calculated using the error term of the interaction from the omnibus ANOVA.

${ }^{*} p<.05 .{ }^{* * *} p<.01$

\section{Experiment 2}

In the study of Rieger and Gauggel (1999) and in Experiments $1 \mathrm{~A}$ and $1 \mathrm{~B}$ of the present study, stimulus repetitions were always associated with response repetitions because the mapping of stimuli onto responses was 1:1. Consequently, we could not determine whether the repetition-priming effects were stimulus related, response related, or both. To assess the role of stimulus and response repetitions in the aftereffect of successful stopping, we mapped four stimuli on two responses. This procedure resulted in stimulusrepetition, response-repetition, and no-repetition trials. The difference between stimulus- and response-repetition trials is that both the stimulus and response of trial $n-1$ are repeated on stimulusrepetition trials, whereas only the response of trial $n-1$ is repeated on response-repetition trials. If the repetition priming effects after a signal-inhibit trial are due to a repetition of the stimulus, then we should find that $\mathrm{GO}_{\mathrm{SI}-1}$ RTs are longer then $\mathrm{GO}_{\mathrm{NS}-1}$ RTs for stimulus-repetition trials, but not for response-repetition and norepetition trials. Conversely, if the repetition effects are responserelated, then we should find that $\mathrm{GO}_{\mathrm{SI}-1} \mathrm{RTs}$ are longer than $\mathrm{GO}_{\mathrm{NS}-1}$ RTs for both stimulus- and response-repetition trials.

\section{Method}

Subjects. Subjects were drawn from the same pool and met the same criteria as in Experiment 1B. Sixteen subjects participated in exchange for a payment of $€ 7.5$ for $45 \mathrm{~min}$.

Apparatus, stimuli and procedure. Only the changes in comparison with Experiment 1B are mentioned. The primary task was to respond with the left and right hand to the identity of a geometrical figure which was either a circle (diameter: $1 \mathrm{~cm}$ ), a square $(1 \times 1 \mathrm{~cm})$, an equilateral triangle (height: $1 \mathrm{~cm})$, or a rhombus (diagonals: $1 \mathrm{~cm}$ ). The mapping of stimuli onto responses was 4:2. Each stimulus was assigned to one of the two responses, and each response was associated with two stimuli. The subjects were randomly assigned to one of the six possible mapping rules. ${ }^{2}$ The experimental phase consisted of eight blocks of 96 trials.

\section{Results and Discussion}

We used the same trimming procedure as in Experiments $1 \mathrm{~A}$ and $1 \mathrm{~B}$, which resulted in a data reduction of $2.2 \%$. Mean SSRT was $208 \mathrm{~ms}$, with a mean probability of responding of .493 and a mean SSD of $361 \mathrm{~ms}$. Of the trials included in the analysis, $49.8 \%$ were no-repetition trials, $24.7 \%$ were response repetitions, and $25.5 \%$ were stimulus repetitions. As can be seen in Table 1, mean error rates were slightly higher than in Experiments 1A and 1B, but there were no indications of a speed-accuracy trade off. Therefore, the analyses again focus only on the RT data.

RTs of no-signal trials were analyzed by means of a 3 (signal $_{n-1}$ : no signal, signal respond, or signal inhibit) $\times 3$ (repetition: stimulus repetition, response repetition, or no repetition) repeated measures ANOVA. The global ANOVAs are reported in Table 2. There were main effects of signal $_{n-1}$ and repetition, but as can be seen in Figure 2, the two main effects interacted significantly. The planned comparisons are reported in Table 3. For stimulusrepetition trials, we found that $\mathrm{GO}_{\mathrm{NS}-1} \mathrm{RTs}(502 \mathrm{~ms})$ were shorter than $\mathrm{GO}_{\mathrm{SR}-1}$ RTs $\left(548 \mathrm{~ms}\right.$ ) and $\mathrm{GO}_{\mathrm{SI}-1}$ RTs $(591 \mathrm{~ms})$. A different pattern of results was found for response-repetition and norepetition trials. For response-repetition trials, $\mathrm{GO}_{\mathrm{NS}-1} \mathrm{RTs}(572$ $\mathrm{ms}$ ) were shorter than $\mathrm{GO}_{\mathrm{SR}-1} \mathrm{RTs}(613 \mathrm{~ms})$ but were comparable to $\mathrm{GO}_{\mathrm{SI}-1} \mathrm{RTs}(584 \mathrm{~ms})$. Similarly, for no-repetition trials, $\mathrm{GO}_{\mathrm{NS}-1}$ RTs (562 ms) were shorter than $\mathrm{GO}_{\mathrm{SR}-1}$ RTs $(587 \mathrm{~ms})$, but they were comparable to $\mathrm{GO}_{\mathrm{SI}-1}$ RTs $(569 \mathrm{~ms})$.

In sum, by using the information-reduction procedure, we found evidence for the hypothesis that the aftereffects of successful response inhibition are primarily due to stimulus-repetition priming. In addition, the fact that aftereffects of successful inhibition were similar for response-repetition and no-repetition trials also suggests that these aftereffects are not caused by residual inhibition of the response. In line with Experiment $1 \mathrm{~A}$ and previous results (Rieger \& Gauggel, 1999; Schachar et al., 2004), we again found that $\mathrm{GO}_{\mathrm{SR}-1}$ RTs were longer than $\mathrm{GO}_{\mathrm{NS}-1}$ RTs. Because this slowing down was observed for no-repetition, responserepetition, and stimulus-repetition trials, it suggests that subjects indeed made post-error control adjustments when response inhibition failed. Thus, control adjustments were made when response inhibition failed, but not when it succeeded.

\footnotetext{
${ }^{2}$ The six possible mapping rules were: (1) circle $\&$ square $=$ left, rhombus \& triangle = right; (2) circle \& rhombus $=$ left, square \& triangle = right; (3) circle $\&$ triangle $=$ left, square $\&$ rhombus = right; (4) square $\&$ rhombus $=$ left, circle $\&$ triangle $=$ right; (5) square $\&$ triangle $=$ right, circle $\&$ rhombus = right; (6) triangle $\&$ rhombus $=$ left, circle $\&$ square $=$ left.
} 


\section{Experiment 3}

In Experiment 2, we found no differences between no-repetition and response-repetition trials, replicating previous findings. Several studies reported large stimulus-repetition effects in the absence of a response-repetition effect (Campbell \& Proctor, 1993; Pashler \& Baylis, 1991; Rabbitt, 1968), and Pashler and Baylis (1991; see also Campbell \& Proctor, 1993) demonstrated that response repetition effects are found only when stimulus categories are mapped on the responses (e.g., digits to a left finger and letters to a right finger). In other words, Pashler and Baylis (1991) found a stimulus-category-repetition benefit. Therefore, in Experiment 3, we further investigated stimulus- and category-repetition priming effects by using a manipulation similar to the one used by Pashler and Baylis (1991). In Experiment 2, the four stimuli were noncategorizable and arbitrarily mapped on one of the two responses. By contrast, in Experiment 3, the stimuli (digits and letters) were categorically mapped on the responses, which resulted in three trial types: stimulus-repetition, category-repetition, and no-repetition trials. If the repetition-priming effects of response inhibition mirror those typically found in choice RT tasks, then $\mathrm{GO}_{\mathrm{SI}-1}$ RTs should be longer than $\mathrm{GO}_{\mathrm{NS}-1}$ RTs for both stimulus-repetition and category-repetition trials. As noted above, category repetitions are also response repetitions. However, we did not find an effect of response repetitions in Experiment 2. Thus, a difference between $\mathrm{GO}_{\mathrm{SI}-1}$ RTs and $\mathrm{GO}_{\mathrm{NS}-1}$ RTs on stimuluscategory-repetition trials would provide further evidence for the hypothesis that the aftereffects of response inhibition are primarily due to stimulus-related priming.

\section{Method}

Subjects. Subjects were drawn from the same pool and met the same criteria as in Experiment 1B. Twelve subjects participated in exchange for a payment of $€ 7.5$ for $45 \mathrm{~min}$. One subject was excluded for having a deviant mean RT (2.5 standard deviations above the group mean).

Apparatus, stimuli and procedure. Only the changes in comparison with Experiment 2 are mentioned. The primary task was to react with the left and right hand to the identity of the stimulus, which was either a letter $(\mathrm{A}$ or $\mathrm{B} ; 0.6 \times 0.7 \mathrm{~cm})$ or a digit $(1$ or 2 ; also maximum $0.6 \times 0.7 \mathrm{~cm}$ ). The stimulus categories (i.e., letters and digit) were assigned to one of the two responses, and the mapping rules were counterbalanced across subjects.

\section{Results and Discussion}

The data trimming procedure resulted in a data reduction of $2.6 \%$. Mean SSRT was $196 \mathrm{~ms}$, with a mean probability of responding of .497 and a mean SSD of $314 \mathrm{~ms}$. Subjects made very few errors $(2.1 \%)$, and there were no indications of a speedaccuracy trade-off. Of the trials included in the analyses, 50.0\% were no-repetition trials, $24.7 \%$ were category repetitions, and $25.3 \%$ were stimulus repetitions. RT data from no-signal trials

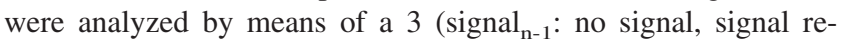
spond, or signal inhibit) $\times 3$ (repetition: stimulus repetition, category repetition, or no repetition) repeated measures ANOVA, and the global ANOVAs are reported in Table 2.

As can be seen, the analysis yielded main effects of signal $_{n-1}$ and repetition. The interaction between the two main effects again reached significance. This interaction is depicted in Figure 2, and the planned comparisons are reported in Table 3. For stimulusrepetition trials, $\mathrm{GO}_{\mathrm{NS}-1} \mathrm{RTs}(458 \mathrm{~ms})$ were shorter than $\mathrm{GO}_{\mathrm{SR}-1}$ RTs $(511 \mathrm{~ms})$ and $\mathrm{GO}_{\mathrm{SI}-1}$ RTs $(529 \mathrm{~ms})$. Similar differences were found for category-repetition trials: $\mathrm{GO}_{\mathrm{NS}-1} \mathrm{RTs}(486 \mathrm{~ms})$ were shorter than $\mathrm{GO}_{\mathrm{SR}-1}$ RTs $(543 \mathrm{~ms})$ and $\mathrm{GO}_{\mathrm{SI}-1}$ RTs $(536 \mathrm{~ms})$, Finally, for no-repetition trials, $\mathrm{GO}_{\mathrm{NS}-1} \mathrm{RTs}(510 \mathrm{~ms})$ were comparable to $\mathrm{GO}_{\mathrm{SR}-1}$ RTs $(514 \mathrm{~ms})$ and $\mathrm{GO}_{\mathrm{SI}-1}$ RTs $(514 \mathrm{~ms})$.

In sum, there was a difference between $\mathrm{GO}_{\mathrm{SI}-1} \mathrm{RT}$ s and $\mathrm{GO}_{\mathrm{NS}-1}$ RTs for both stimulus-repetition and category-repetition trials. Because no such difference was found for no-repetition trials, we can conclude that the aftereffect of successful stopping was again primarily due to repetition priming and not to between-trial control adjustments. We did not find an aftereffect of successful stopping for response-repetition trials in Experiment 2, so these results demonstrate that the aftereffects are primarily due to stimulusrelated priming. Finally, it is also worth mentioning that the repetition-priming effects found after successful response inhibition mirror those found after a no-signal trial. In a standard choice RT task, response-repetition benefits are typically found when the stimuli are categorizable (e.g., Pashler \& Baylis, 1991). This is also what we observed for $\mathrm{GO}_{\mathrm{NS}-1}$ RTs: In Experiment 2, there was no significant difference between no-repetition and responserepetition trials $(-10 \mathrm{~ms}, p=.29)$ whereas we did find a difference between no-repetition and category-repetition trials in Experiment $3(+24 \mathrm{~ms}, p<.01)$. Interestingly, the results of Experiment 3 demonstrated that a category-repetition benefit was found after a no-signal trial, but a category-repetition cost was found after a signal-inhibit trial. This finding suggests that a similar underlying mechanism could be responsible for these different priming effects. We come back to this issue in the General Discussion.

\section{Experiment 4}

So far, the results suggest that the aftereffects of successful stopping are primarily due to repetition priming. In this final experiment, we wanted to investigate whether the presentation of a stop signal could also contribute to the observed pattern of results. When trial $n$ is a no-signal trial and trial $n-1$ is a signal-inhibit trial, then trial $n$ will always be different from trial $n$ -1 because of the absence of the stop signal. Consequently, after a stop-signal trial, stimulus repetitions on trial $n$ were never exact repetitions, and this might have contributed to the observed differences between $\mathrm{GO}_{\mathrm{SI}-1}$ and $\mathrm{GO}_{\mathrm{NS}-1}$ RTs (see Notebaert \& Soetens, 2003; Pashler \& Baylis, 1991).

To control for the possible effects of stop-signal presentation, we used the selective stop-signal paradigm in Experiment 4. In this variant of the standard stop-signal paradigm, two different tones are presented (Bedard et al., 2002; Logan, Kantowitz, \& Riegler, 1986) and subjects are instructed to ignore one of the two tones (invalid-signal trials) and inhibit their response when they hear the other tone (valid-signal trials). Thus, on both invalid-signal trials and signal-inhibit trials (i.e., valid-signal trials on which the inhibition succeeded), an auditory tone is sounded. If the aftereffects found in Experiments 1A-3 were caused by stop-signal presentation on trial $n-1$, then no-signal RTs of trials following an invalid-signal trial $\left(\mathrm{GO}_{\mathrm{IV}-1} \mathrm{RTs}\right)$ should differ from $\mathrm{GO}_{\mathrm{NS}-1} \mathrm{RTs}$ but not from $\mathrm{GO}_{\mathrm{SI}-1} \mathrm{RTs}$. Alternatively, if the aftereffects are caused by response inhibition and not by stop-signal presentation, 
then we should find no difference between $\mathrm{GO}_{\mathrm{IV}-1}$ and $\mathrm{GO}_{\mathrm{NS}-1} \mathrm{RTs}$, whereas $\mathrm{GO}_{\mathrm{IV}-1}$ RTs should differ from $\mathrm{GO}_{\mathrm{SI}-1}$ RTs. Finally, if both stop-signal presentation and response inhibition contribute to the observed aftereffects, then we should find differences between $\mathrm{GO}_{\mathrm{IV}-1}$ and $\mathrm{GO}_{\mathrm{NS}-1}$ RTs and between $\mathrm{GO}_{\mathrm{IV}-1}$ and $\mathrm{GO}_{\mathrm{SI}-1}$ RTs. As in Experiments $1 \mathrm{~A}$ and $1 \mathrm{~B}$, we dissociated between repetition-priming effects and between-control trial adjustments by making a distinction between stimulus-repetition and no-repetition trials.

\section{Method}

Subjects. Subjects were drawn from the same pool and met the same criteria as in Experiment 1B. Sixteen subjects participated in exchange for a payment of $€ 5$ for $30 \mathrm{~min}$.

Apparatus, stimuli and procedure. The primary task was similar to the one used in Experiment 1B. Therefore, only differences with Experiment 1B are mentioned. On $25 \%$ of the trials, a loud, clear auditory signal $(60 \mathrm{~dB}, 75 \mathrm{~ms})$ was presented. One half of the signals were high tones $(750 \mathrm{~Hz})$, the other half were low tones $(250 \mathrm{~Hz})$. SSD for invalid-signal trials was the same as the current SSD for valid-signal trials. SSD was not adjusted after an invalidsignal trial. The experimental phase consisted of 10 blocks of 64 trials. Half of the subjects were instructed to ignore the high tones and to stop their response if a low tone was presented. For the other half of the subjects, instructions were reversed.

\section{Results and Discussion}

The trimming procedure resulted in a data reduction of $2.1 \%$. The mean SSRT was $245 \mathrm{~ms}$, with a mean probability of responding of .504 and a mean SSD of 215 ms. Subjects made few errors (1.6\%), and there were no indications of a speed-accuracy trade-off. Invalidly stopped responses (i.e., response withheld when an invalid stop signal was presented) were extremely rare $(0.2 \%)$; therefore, we did not include the trials that followed an incorrectly stopped response in the analyses. Of the trials included in the analysis, 50.2\% were norepetition trials. RT data from no-signal trials were analyzed by means of a 4 (signal $_{\mathrm{n}-1}$ : no signal, invalid signal, signal respond, or signal inhibit) $\times 2$ (repetition: stimulus repetition or no repetition) repeated measures ANOVA. The relevant means appear in Table 1, and the global ANOVAs are reported in Table 2.

There were main effects of signal $_{n-1}$ and repetition. The significant interaction between the main effects of signal $_{n-1}$ and repetition is depicted in Figure 2. Planned comparisons of interest are reported in Table 3. For stimulus-repetition trials, we found that $\mathrm{GO}_{\mathrm{NS}-1}$ RTs $(434 \mathrm{~ms})$ were shorter than $\mathrm{GO}_{\mathrm{SR}-1}$ RTs $(511 \mathrm{~ms})$, $\mathrm{GO}_{\mathrm{SI}-1}$ RTs (491 ms), and $\mathrm{GO}_{\mathrm{IV}-1}$ RTs (459 ms). In turn, $\mathrm{GO}_{\mathrm{IV}-1}$ RTs were shorter than $\mathrm{GO}_{\mathrm{SR}-1} \mathrm{RTs}$ and $\mathrm{GO}_{\mathrm{SI}-1} \mathrm{RTs}$, suggesting that there was indeed a difference between trials that followed an invalid stop signal and trials that followed a valid stop signal. For no-repetition trials, $\mathrm{GO}_{\mathrm{NS}-1} \mathrm{RTs}(455 \mathrm{~ms})$ were shorter than $\mathrm{GO}_{\mathrm{SR}-1} \mathrm{RTs}$ (477 ms), but they were comparable to $\mathrm{GO}_{\mathrm{IV}-1} \mathrm{RTs}$ (457 ms) and $\mathrm{GO}_{\mathrm{SI}-1}$ RTs (449 ms). Similarly, GO $\mathrm{IV}-1_{1}$ RTs (457 $\mathrm{ms}$ ) were shorter than $\mathrm{GO}_{\mathrm{SR}-1} \mathrm{RTs}(477 \mathrm{~ms})$ but they were comparable to $\mathrm{GO}_{\mathrm{SI}-1} \mathrm{RTs}(449 \mathrm{~ms}$ ).

In sum, the results of Experiment 4 revealed that the presentation of an invalid stop signal on trial $n-1$ can partially influence RT on trial $n$. First, as can be seen in Tables 1 and 3, $\mathrm{GO}_{\mathrm{IV}-1} \mathrm{RTs}$ differed from $\mathrm{GO}_{\mathrm{NS}-1}$ RTs for stimulus-repetition trials but not for no-repetition trials. This suggests that the stimulus-repetition benefit observed after a no-signal trial was absent after an invalidsignal trial. In addition to the difference between $\mathrm{GO}_{\mathrm{IV}-1} \mathrm{RTs}$ and $\mathrm{GO}_{\mathrm{NS}-1}$ RTs, we also found a difference between $\mathrm{GO}_{\mathrm{IV}-1}$ and $\mathrm{GO}_{\mathrm{SI}-1}$ RTs. However, this difference was observed only for stimulus-repetition trials. This suggests that besides the absence of a stimulus-repetition benefit after an invalid-signal trial $\left(\mathrm{GO}_{\mathrm{IV}-1}\right.$ vs. $\left.\mathrm{GO}_{\mathrm{NS}-1}\right)$, there was an additional stimulus-repetition cost when the response on the previous trial was successfully inhibited $\left(\mathrm{GO}_{\mathrm{IV}-1}\right.$ vs. $\left.\mathrm{GO}_{\mathrm{SI}-1}\right)$.

Is there response inhibition on invalid-signal trials? Before we can interpret the slowing after invalid stop signal trials as evidence for an effect of stop-signal presentation, we need to rule out the possibility that subjects simply stopped whenever a tone occurred, determined the pitch of the tone, and then responded if the tone was an invalid stop signal. This strategy would prolong RT on $\mathrm{GO}_{\mathrm{IV}-1}$ trials, because $\mathrm{GO}_{\mathrm{IV}-1}$ trials would be a mixture of $\mathrm{GO}_{\mathrm{SI}-1}$ trials and $\mathrm{GO}_{\mathrm{SR}-1}$ trials. De Jong, Coles, and Logan (1995) discussed this strategy and suggested that it should result in SSRTs that are similar to ones in the standard stop-signal paradigm but also in greatly slowed primary-task responses on invalid-signal trials.

Therefore, we conducted additional SSRT and RT analyses to rule out this possibility. A between-subjects ANOVA revealed that SSRT was significantly longer in Experiment 4 (245 ms) than in Experiments 1A (165 ms), 1B (159 ms), 2 (208 ms), and 3 (196 $\mathrm{ms}$, all $\mathrm{ps}<.05)$. These SSRT differences argue against the possibility that subjects stopped all responses and then reactivated the response in case of an invalid signal (De Jong et al., 1995). ${ }^{3}$ Instead, it suggests different modes of inhibition (De Jong et al., 1995; Logan, 1994). However, as in the study of De Jong et al. (1995; see also Verbruggen, Liefooghe, \& Vandierendonck, 2006b), we observed that in general, mean RTs were faster on no-signal trials (453 ms) than on invalid-signal trials (584 ms, $p<$ .001). Note that this RT difference does not necessarily imply inhibition on invalid-signal trials, as it is possible that this effect reflects dual-task interference between primary-task processing and stop-signal processing (De Jong et al., 1995).

Nevertheless, to further rule out the possibility that the aftereffects of invalid stop signals were caused by response inhibition, we

\footnotetext{
${ }^{3}$ We would also like to comment on the differences in SSRTs between the experiments that used the standard stop-signal paradigm. A betweensubjects comparison revealed that SSRTs were substantially shorter $(p<$ $.001)$ in Experiments 1A (165 ms) and 1B (159 ms) than in Experiments 2 (208 ms) and 3 (196 ms). A close look at Table 1 reveals that this was not just an artifact of differences in primary task latencies because RTs of Experiments 1B and 3 were highly comparable (see Table 1 and Figure 2). Furthermore, in a standard stop-signal paradigm, Logan, Kantowitz, and Riegler (1986) did not find differences between SSRTs in a task with two stimuli and two responses and SSRTs in a task with four stimuli and four responses. Therefore, the longer SSRTs in Experiments 2 and 3 are not due to the number of stimuli. Most likely, these observed SSRT differences are due to the differences in mapping (1:1 vs. $2: 1)$. One could hypothesize that inhibition needs to be more selective with a 2:1 mapping because the inhibited response is associated with different stimuli (and therefore, also with stimuli that are not presented on the stop-signal trial). However, this is only one possible explanation, and there might be other plausible explanations for this finding.
} 
performed a median split on the assumption that response inhibition would occur on about half of the invalid signal trials, since the tracking procedure adjusted SSD so that response inhibition occurred on about half of the stop-signal trials. The faster half of the invalid-signal trials would correspond to "signal-respond" trials on which inhibition failed because the stop signal was presented too late. The slower half of the invalid-signal trials would correspond to "signal-inhibit" trials on which subjects successfully stopped the response and then re-executed it once they determined that the stop signal was invalid. Consequently, aftereffects of invalid stop signals should depend on the response speed on the previous invalidsignal trial. To test this mixture hypothesis, we included RT of trial $n-1$ (i.e., shorter or longer than the median) in the analyses and reanalyzed $\mathrm{GO}_{\mathrm{NS}-1}$ and $\mathrm{GO}_{\mathrm{IV}-1}$ RTs by means of a 2 (signal $_{\mathrm{n}-1}$ : no signal vs. invalid signal) $\times 2\left(\mathrm{RT}_{\mathrm{n}-1}\right.$ : fast vs. slow) $\times 2$ (repetition: no repetition or stimulus repetition) repeated measures ANOVA. $\mathrm{GO}_{\mathrm{SI}-1}$ and $\mathrm{GO}_{\mathrm{SR}-1}$ RTs were not included, and to avoid redundancy, we focus only on the relevant interactions. $\mathrm{GO}_{\mathrm{NS}-1}$ and $\mathrm{GO}_{\mathrm{IV}-1} \mathrm{RTs}$ are depicted in Figure 3. The two-way interaction between signal $_{\mathrm{n}-1}$ and $\mathrm{RT}_{\mathrm{n}-1}$ was significant, $F(1,15)=11.7, M S E$ $=584, p<.001, \eta^{2}=.44$. However, there was a difference between $\mathrm{GO}_{\mathrm{NS}-1} \mathrm{RT}$ s and $\mathrm{GO}_{\mathrm{IV}-1}$ RTs only when $\mathrm{RT}_{\mathrm{n}-1}$ was fast and, therefore, when the response could not have been inhibited. As can be seen in Figure 3, no differences were found when the response on the previous trial was slow. These findings are inconsistent with the mixture hypothesis, which predicted the opposite pattern of results. Note that there was no stimulus-repetition benefit for $\mathrm{GO}_{\mathrm{NS}-1}$ trials. Attempting to explain this finding is beyond the scope of this article. The three-way interaction did not reach significance $(F<1)$. Therefore, both the SSRT and no-signal RT data argue against the explanation that the RT difference between
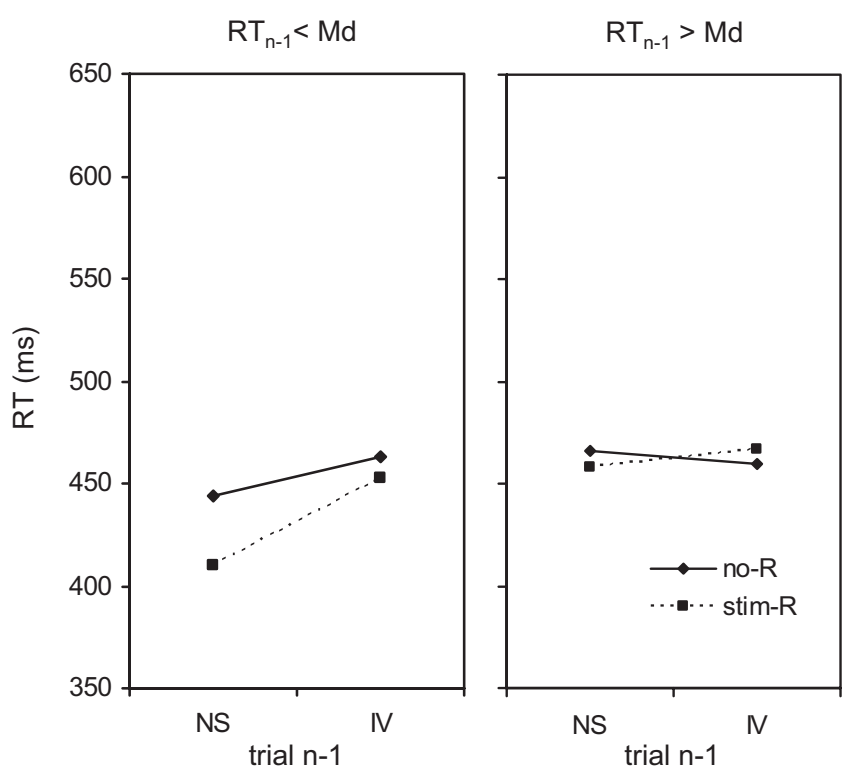

Figure 3. Reaction time (RT) of no-signal trials following a no-signal trial (NS) or an invalid-signal trial (IV) and as a function of the response speed on trial $n-1$ in Experiment 4 . $\mathrm{T}_{\mathrm{n}-1}<\mathrm{Md}$ indicates that the RT of trial $n-1$ was shorter than the median $\mathrm{RT} ; \mathrm{RT}_{\mathrm{n}-1}>\mathrm{Md}$ indicates that the RT of trial $n-1$ was longer than the median RT.
$\mathrm{GO}_{\mathrm{IV}-1}$ and $\mathrm{GO}_{\mathrm{NS}-1}$ trials was due to inhibition of responses on invalid-signal trials.

\section{General Discussion}

The present study focused on the processes that take place after subjects inhibit a response in the stop-signal paradigm (Logan, 1994; Logan \& Cowan, 1984). So far, most studies have focused on executive processes in trials on which the stop signal is presented and how subjects inhibit their response. However, $\mathrm{GO}_{\mathrm{SI}-1}$ and $\mathrm{GO}_{\mathrm{SR}-1} \mathrm{RT}$ are sometimes longer than $\mathrm{GO}_{\mathrm{NS}-1} \mathrm{RTs}$, so executive processes could also occur after the stopping process has finished, by changing the decision criterion (Rieger \& Gauggel, 1999) or the control settings (Emeric et al., 2007). However, not all studies have found evidence for such between-trial control adjustments (Verbruggen et al., 2005), and some studies have shown that priming mechanisms also contribute to the aftereffects of response inhibition (Rieger \& Gauggel, 1999). In the remainder of this article, we briefly summarize the data from Experiments $1 \mathrm{~A}-4$ and offer a possible explanation for the discrepancy in results observed in different studies. Then, we discuss in more detail the relative contribution of repetition priming and between-trial control adjustments to the aftereffects of successful and unsuccessful inhibition.

The results of Experiments 1A-4 demonstrated that the aftereffects of successful response inhibition were primarily due to the repetition of the stimulus or the stimulus category. Across variations in experimental design, each experiment found that $\mathrm{GO}_{\mathrm{SI}-1}$ RTs were longer than $\mathrm{GO}_{\mathrm{NS}-1} \mathrm{RTs}$, but only when the stimulus or stimulus category (Experiment 3) was repeated. Experiment 2 demonstrated that this aftereffect was not due to residual response inhibition, and Experiment 4 demonstrated that the repetitionpriming effect was not solely due to the presentation of a stop signal. Combined, these results suggest that there was a stimulusrelated repetition cost after a successfully stopped response. Different results were found for trials following a signal-respond trial. In Experiments $1 \mathrm{~A}, 2$, and 4, we found that $\mathrm{GO}_{\mathrm{SR}-1} \mathrm{RTs}$ were longer than $\mathrm{GO}_{\mathrm{NS}-1}$ RTs for both stimulus-repetition and norepetition trials, suggesting post-error monitoring after a signalrespond trial. However, in Experiments $1 \mathrm{~B}$ and 3, no differences were found. We come back to this finding later.

Altogether, the results of Experiments $1 \mathrm{~A}-4$ suggest that the aftereffects of stopping are caused by stimulus or stimuluscategory repetitions (primarily after a successfully stopped response) and sometimes by between-trial control adjustments (but only after an unsuccessfully stopped response). At this point, it is worth mentioning that the increase in response latency was not accompanied by a decrease in error rate. We did not report ANOVAs on error rates, because none of the statistics yielded significant effects of signal $_{n-1}$ and because of missing cells in the data matrix in Experiment 3 (note that there was a marginally significant interaction between signal ${ }_{\mathrm{n}-1}$ and response repetition in Experiment 2). However, this interaction is beyond the scope of the present study, because it resulted from the fact that more errors are made after no-signal trials when only one of the relevant features from trial $n-1$ is repeated (see also Notebaert \& Soetens, 2003). Rabbitt (1966) argued that control adjustments should result in longer latencies because of a more conservative response threshold. However, increasing the response threshold in a choice RT task should also result in fewer errors, reflecting a shift in the 
speed-accuracy tradeoff. No such tradeoff was observed in any of the present experiments, and lengthening of RT did not lead to a concomitant reduction in error rate. Of course accuracy was high, so it might have been difficult to find an improvement in accuracy after signal-inhibit or signal-respond trials. Nevertheless, the absence of a speed-accuracy trade-off shift is in line with the hypothesis that subjects did not adjust control settings after all stop-signal trials, as initially proposed by Rieger and Gauggel (1999).

This leaves open an important question: Why did Rieger and Gauggel find a general aftereffect of successful response inhibition $?^{4}$ Rieger and Gauggel hypothesized that the response criterion would be increased after a stop-signal trial and decreased after a no-signal trial. While this might be a plausible explanation for the effects they observed, such shifts should occur only if subjects perceive a resulting benefit. Several factors in the stop-signal paradigm may influence this perception, such as the tracking procedure, task instructions, response deadlines, and primary-task difficulty (because of the ratio of SSD adjustments to mean RT). Therefore, the relative contribution of repetition priming effects and between-trial control adjustments to the aftereffects of successful inhibition may be determined by subjects' strategies, and the presence of between-trial control adjustments may depend on their perceived benefits. Finally, it is interesting to note that Rieger and Gauggel (1999) did not find a stimulus-repetition benefit on $\mathrm{GO}_{\mathrm{NS}}$ trials. In contrast, such a benefit was observed in all five experiments of the present study. Therefore, it could be hypothesized that subject's strategies might have influenced general primary-task performance as well.

\section{Repetition Priming and Response Inhibition}

So far, we have argued that the aftereffects of successful response inhibition observed in the present study are primarily due to repetition priming effects. These findings seem to fit in with the instance theory of automatization (Logan, 1988, 1990). Logan proposed that attending to stimuli would automatically lead to the storage of a new processing episode and the retrieval of previous episodes. This would facilitate responding because of previous encounters and could explain repetition effects as well as practice effects (Logan, 1988, 1990). Furthermore, a processing episode would consist of a specific combination of the stimulus, the interpretation given to the stimulus, the associated response, and the task goal. A similar idea was also proposed by Mayr and Bryck (2005), who focused on the recurrent finding that responserepetition benefits in task-switching paradigms are found only when the task remains the same. When the task switches, response repetition benefits disappear or turn into costs. Mayr and Bryck (2005) suggested that the stimulus and response were associated with the task rule. Consequently, when the task rule changes, subjects no longer benefit from the retrieval of the previous stimulus-response association.

These proposals of Logan $(1988,1990)$ and Mayr and Bryck (2005) imply that higher order information such as task goals or task rules can be associated with lower level stimulus-response codes. Thus, a processing episode contains some information of the state of the executive system. Based on the executive act of control model (Logan \& Cowan, 1984), this would imply that on a no-signal trial, an episode contains information about the go goal, the primary-task stimulus, and the response to that stimulus. On a signal-inhibit trial, a different processing episode is stored, in which the stimulus is associated with a stop goal. When the stimulus repeats on the next no-signal trial, the irrelevant stop goal is retrieved and the go response is suppressed (Logan \& Cowan, 1984). Hence, we assume a tight relation between repetition effects and executive control because processing episodes contain information about task goals. Furthermore, executive processes are needed for preserving the task goal in the presence of irrelevant information or throughout the execution of processes involved in achieving the goal (see Miller \& Cohen, 2001). Logan and Cowan (1984) assumed that the stop goal replaces the go goal and that this results in the suppression of the go response. Thus, when the incorrect stop goal is retrieved on a no-signal trial, executive control is needed to preserve the currently relevant go goal. Therefore, we do not deny the presence of executive processes in no-signal trials. However, the major difference with the betweentrial adjustment hypothesis of Emeric et al. (2007) and our proposal is that we assume that there is interference between the stop and go goal on no-signal trials, whereas Emeric et al. (2007) assumed that there was interference between the stop and go processes on signal trials.

The idea about stop goal retrieval resembles the episodic retrieval account of negative priming proposed by Neill et al. (Neill \& Valdes, 1992; Neill, Valdes, Terry, \& Gorfein, 1992). Their episodic retrieval theory is based on the instance theory of Logan (1988). Neill and colleagues assumed that a negative priming effect reflects interference between "do respond" and "do not respond" tags associated with the stimuli in previous processing episodes. They argued that the these tags were the subgoals of trial $n-1$, namely, "respond" to the target and "do not respond" to the distractor. The distractor of trial $n-1$ becomes associated with this goal (or tag), and we assume that this "do not respond" tag results in the suppression of the go response.

A final remark concerns the stimulus-response associations on signal-inhibit trials. Based on previous results of Logan (1985b), it seems reasonable to assume that the episode contains at least some response information. Logan (1985b; Experiment 1) performed an experiment in which subjects had to make category or rhyme judgments about word pairs and occasionally a stop signal was presented. After several stop-signal blocks, a repetition block was presented in which subjects performed the same judgment tasks without stop signals. Some of the word pairs of the stop-signal blocks were repeated, and Logan analyzed whether stop-signal presentation influenced the repetition effect. Interestingly, he found similar repetition effects for word pairs on which no stop signal was presented and word pairs on which the response was successfully stopped (see also Logan, 1983). First, this demonstrates that the stimulus is associated with the appropriate response, even though the response was never executed. Second, this finding also suggests that aftereffects of successful inhibition observed in the present study and in the study of Rieger and Gauggel (1999) were not due to weakened associations between a stimulus and a response.

\footnotetext{
${ }^{4}$ Emeric et al. (2007) did not analyze the effect of stimulus repetitions; therefore, it remains unclear how this would have affected the aftereffect of stopping saccadic responses.
} 
Note that at first sight, the results of Logan $(1983 ; 1985 b)$ are not in accord with the stimulus-related repetition effects of successful inhibition observed in the present study and in the study of Rieger and Gauggel (1999). At this point, we do not have a clear explanation for this discrepancy in results, but it could be that episodes or associations that are still in working memory have different effects than episodes that are retrieved from long-term memory (see also Mayr \& Bryck, 2005, who came to a similar conclusion). Another explanation could be that the higher level information in a processing episode is more susceptible to decay than the lower level stimulus-response information. Finally, it could be that in the study by Logan (1985b), the stop goal no longer had a strong effect on performance because no stop signals were presented in the repetition block. Further research into this discrepancy is needed. Nevertheless, we feel confident enough to conclude that the aftereffect of successful response inhibition is to a large extent a consequence of episodic memory.

\section{Post-Error Monitoring and Response Inhibition}

Aftereffects of successful response inhibition seem to be determined by the repetition of the stimulus of trial $n-1$. However, a different pattern of results was found after signal-respond trials in three of the five experiments. In Experiments 1A, 2, and 4, we found that $\mathrm{GO}_{\mathrm{SR}-1}$ RTs were longer than $\mathrm{GO}_{\mathrm{NS}-1} \mathrm{RT}$ for both no-repetition and stimulus-repetition trials. In Experiments $1 \mathrm{~B}$ and 3 , this difference was observed only for stimulus-repetition trials, and as argued in the introduction, between-trial control adjustments should be observed whether or not the primary-task stimulus is repeated. Consequently, it could be argued that we found evidence for between-trial control adjustments after a signal-respond trial only in Experiments 1A, 2, and 4 (although we did not observe a decrease in error rates, as mentioned earlier). In previous studies, it was also observed that $\mathrm{GO}_{\mathrm{SR}-1}$ RTs were longer than $\mathrm{GO}_{\mathrm{NS}-1}$ RTs (Rieger \& Gauggel, 1999; Schachar et al., 2004; Verbruggen et al., 2005). These authors all argued that this aftereffect of unsuccessful stopping is probably due to error monitoring and post-error slowing (note that Rieger and Gauggel mentioned that the aftereffect of unsuccessful stopping could also be in line with the general adjustment strategy).

This post-error effect, found in a variety of tasks and paradigms, is well-documented and has received much attention because it reflects dynamic behavioral adjustments and shifts in response mode (Holroyd, Yeung, Coles, \& Cohen, 2005; Rabbitt, 1966, 1968; Rabbitt \& Rodgers, 1977). Our subjects may have interpreted failed inhibition as an error and opted for a more cautious response strategy on the next trial, in order to increase the probability of stopping. This reasoning can also explain why there is an effect only after a signal-respond trial: After a signal-inhibit trial, there is no need to adjust the response strategy as the inhibition succeeded and no error was made.

At this point, it is also worth mentioning that Schachar et al. (2004) did not find a correlation between the increase in response latency and the stopping latency, suggesting that response inhibition and its aftereffects were under the control of different mechanisms.

Although we found some evidence for post-error slowing after an unsuccessfully inhibited response, it is not clear why this effect was not found in Experiments 1B and 3. Moreover, some other studies have not found post-error slowing (see Emeric et al., 2007). The unclear pattern of results may be due to the task demands and the instructions subjects received. First, the tracking procedure forces subjects to fail at stopping their responses on approximately half of the stoptrials. This number of failed stops is much higher than the number of errors that are typically made in a choice RT task, so subjects may not consider a failed stop as an error. Furthermore, subjects are typically informed about the tracking procedure and that the SSD would vary from trial to trial. (Logan et al., 1997; Verbruggen et al., 2005) They are also told that, consequently, they will not be able to stop their responses on approximately half of the trials. Thus, subjects may not interpret a signal-respond trial as an error. The fact that the post-error effects after a signal-respond trial are not always found may be due to some specific characteristics of the stop-signal paradigm; future work will be required to determine which parameters of the paradigm influence the presence and magnitude of post-error effects

\section{Conclusions}

In the present study, we investigated the effects of repetition priming and between-trial control adjustments after successful and unsuccessful response inhibition. In a series of experiments, we demonstrated that aftereffects of successful response inhibition were primarily due to repetition priming, although we found some evidence for control adjustments after an unsuccessful response inhibition. Based on these results, we propose a tight relation between repetition priming and executive control by arguing that stimuli are associated with task goals. When a stimulus was previously associated with a stop goal and this association is retrieved, the response is incorrectly suppressed, and this delays responding on no-signal trials.

\section{References}

Andres, P. (2003). Frontal cortex as the central executive of working memory: Time to revise our view. Cortex, 39, 871-895.

Aron, A. R., Robbins, T. W., \& Poldrack, R. A. (2004). Inhibition and the right inferior frontal cortex. Trends in Cognitive Sciences, 8, 170-177.

Baddeley, A. (1996). Exploring the central executive. Quarterly Journal of Experimental Psychology, 49A, 5-28.

Bedard, A. C., Nichols, S., Barbosa, J. A., Schachar, R., Logan, G. D., \& Tannock, R. (2002). The development of selective inhibitory control across the life span. Developmental Neuropsychology, 21, 93-111.

Bertelson, P. (1965, April 10). Serial choice reaction-time as a function of response versus signal-and-response repetition. Nature, 206, 217-218.

Botvinick, M. M., Braver, T. S., Barch, D. M., Carter, C. S., \& Cohen, J. D. (2001). Conflict monitoring and cognitive control. Psychological Review, 108, 624-652.

Botvinick, M. M., Cohen, J. D., \& Carter, C. S. (2004). Conflict monitoring and the anterior cingulate cortex: An update. Trends in Cognitive Sciences, 8, 539-546.

Botvinick, M., Nystrom, L. E., Fissell, K., Carter, C. S., \& Cohen, J. D. (1999, November 11). Conflict monitoring versus selection-for-action in anterior cingulate cortex. Nature, 402, 179-181.

Cabel, D. W. J., Armstrong, I. T., Reingold, E., \& Munoz, D. P. (2000). Control of saccade initiation in a countermanding task using visual and auditory stop signals. Experimental Brain Research, 133, 431-441.

Campbell, K. C., \& Proctor, R. W. (1993). Repetition effects with categorizable stimulus and response sets. Journal of Experimental Psychology: Human Perception and Performance, 19, 1345-1362. 
Chambers, C. D., Bellgrove, M. A., Stokes, M. G., Henderson, T. R., Garavan, H., Robertson, I. H., et al. (2006). Executive "brake failure" following deactivation of human frontal lobe. Journal of Cognitive Neuroscience, 18, 444-455.

Dalrymple-Alford, E. C., \& Budayr, B. (1966). Examination of some aspects of the Stroop color-word test. Perceptual \& Motor Skills, 23, 1211-1214.

De Jong, R., Coles, M. G. H., \& Logan, G. D. (1995). Strategies and mechanisms in nonselective and selective inhibitory motor control. Journal of Experimental Psychology: Human Perception and Performance, 21, 498-511.

Emeric, E. E., Brown, J. W., Boucher, L., Carpenter, R. H. S., Hanes, D. P., Harris, R., et al. (2007). Influence of history on saccade countermanding performance in humans and macaque monkeys. Vision Research, 47, $35-49$.

Holroyd, C. B., Yeung, N., Coles, M. G. H., \& Cohen, J. D. (2005). A mechanism for error detection in speeded response time tasks. Journal of Experimental Psychology: General, 134, 163-191.

Jennings, J. R., van der Molen, M. W., Pelham, W., Debski, K. B., \& Hoza, B. (1997). Inhibition in boys with attention deficit hyperactivity disorder as indexed by heart rate change. Developmental Psychology, 33, 308318

Kerns, J. G., Cohen, J. D., Macdonald, A. W., Cho, R. Y., Stenger, V. A., \& Carter, C. S. (2004, February 13). Anterior cingulate conflict monitoring and adjustments in control. Science, 303, 1023-1026.

Kramer, A. F., Humphrey, D. G., Larish, J. F., Logan, G., \& Strayer, D. L. (1992, March). Aging and inhibition. Paper presented at The Conference on Cognition and Aging, Atlanta, GA.

Kramer, A. F., Humphrey, D. G., Larish, J. F., Logan, G. D., \& Strayer, D. L. (1994). Aging and inhibition: Beyond a unitary view of inhibitory processing in attention. Psychology and Aging, 9, 491-512.

Lappin, J. S., \& Eriksen, C. W. (1966). Use of a delayed signal to stop a visual reaction-time response. Journal of Experimental Psychology, 72, 805-811.

Logan, G. D. (1983). On the ability to inhibit simple thoughts and actions: I. Stop-signal studies of decision and memory. Journal of Experimental Psychology: Human Perception and Performance, 9, 585-606.

Logan, G. D. (1985a). Executive control of thought and action. Acta Psychologica, 60, 193-210.

Logan, G. D. (1985b). On the ability to inhibit simple thoughts and actions: II. Stop-signal studies of repetition priming. Journal of Experimental Psychology: Learning Memory and Cognition, 11, 675-691.

Logan, G. D. (1988). Toward an instance theory of automatization. Psychological Review, 95, 492-527.

Logan, G. D. (1990). Repetition priming and automaticity - Common underlying mechanisms. Cognitive Psychology, 22, 1-35.

Logan, G. D. (1994). On the ability to inhibit thought and action: A user's guide to the stop signal paradigm. In D. Dagenbach \& T. H. Carr (Eds.), Inhibitory processes in attention, memory and language (pp. 189-239). San Diego: Academic Press.

Logan, G. D., \& Cowan, W. B. (1984). On the ability to inhibit thought and action - A theory of an act of control. Psychological Review, 91, 295-327.

Logan, G. D., \& Irwin, D. E. (2000). Don’t look! Don’t touch! Inhibitory control of eye and hand movements. Psychonomic Bulletin \& Review, 7 , $107-112$.

Logan, G. D., Kantowitz, B. H., \& Riegler, G. L. (1986). On the ability to stop selectively: Mechanisms of response interdiction in choice reaction time. Unpublished manuscript, Purdue University.

Logan, G. D., Schachar, R. J., \& Tannock, R. (1997). Impulsivity and inhibitory control. Psychological Science, 8, 60-64.

May, C. P., Kane, M. J., \& Hasher, L. (1995). Determinants of negative priming. Psychological Bulletin, 118, 35-54.
Mayr, U., Awh, E., \& Laurey, P. (2003). Conflict adaptation effects in the absence of executive control. Nature Neuroscience, 6, 450-452.

Mayr, U., \& Bryck, R. L. (2005). Sticky rules: Integration between abstract rules and specific actions. Journal of Experimental Psychology: Learning Memory and Cognition, 31, 337-350.

Milham, M. P., Banich, M. T., Webb, A., Barad, V., Cohen, N. J., Wszalek, T., \& Kramer, A. F. (2001). The relative involvement of anterior cingulate and prefrontal cortex in attentional control depends on nature of conflict. Cognitive Brain Research, 12, 467-473.

Miller, E. K., \& Cohen, J. D. (2001). An integrative theory of prefrontal cortex function. Annual Review of Neuroscience, 24, 167-202.

Miyake, A., Friedman, N. P., Emerson, M. J., Witzki, A. H., Howerter, A., \& Wager, T. D. (2000). The unity and diversity of executive functions and their contributions to complex "frontal lobe" tasks: A latent variable analysis. Cognitive Psychology, 41, 49-100.

Neill, W. T., \& Valdes, L. A. (1992). Persistence of negative priming Steady-state or decay. Journal of Experimental Psychology: Learning Memory and Cognition, 18, 565-576.

Neill, W. T., Valdes, L. A., Terry, K. M., \& Gorfein, D. S. (1992) Persistence of negative priming: II. Evidence for episodic trace retrieval. Journal of Experimental Psychology: Learning Memory and Cognition, 18, 993-1000.

Nieuwenhuis, S., Stins, J. F., Posthuma, D., Polderman, T. J. C., Boosma, D. I., \& de Geus, E. J. (2006). Accounting for sequential trial effects in the flanker task: Conflict adaptation or associative priming. Memory \& Cognition, 34, 1260-1272.

Notebaert, W., \& Soetens, E. (2003). The influence of irrelevant stimulus changes on stimulus and response repetition effects. Acta Psychologica, 112, 143-156.

Pashler, H., \& Baylis, G. (1991). Procedural learning. II. Intertrial repetition effects in speeded-choice tasks. Journal of Experimental Psychology: Learning Memory and Cognition, 17, 33-48.

Rabbitt, P. M. A. (1966). Errors and error correction in choice-response tasks. Journal of Experimental Psychology, 71, 264-272.

Rabbitt, P. M. A. (1968). Repetition effects and signal classification strategies in serial choice-response tasks. Quarterly Journal of Experimental Psychology, 20, 232-240.

Rabbitt, P. M. A., \& Rodgers, B. (1977). What does a man do after he makes an error - Analysis of response programming. Quarterly Journal of Experimental Psychology, 29, 727-743.

Ridderinkhof, K. R., Band, G. P. H., \& Logan, G. D. (1999). A study of adaptive behavior: Effects of age and irrelevant information on the ability to inhibit one's actions. Acta Psychologica, 101, 315-337.

Rieger, M., \& Gauggel, S. (1999). Inhibitory after-effects in the stop signal paradigm. British Journal of Psychology, 90, 509-518.

Schachar, R., \& Logan, G. (1990). Are hyperactive children deficient in attentional capacity? Journal of Abnormal Child Psychology, 18, 493513.

Schachar, R. J., Chen, S., Logan, G. D., Ornstein, T. J., Crosbie, J., Ickowicz, A., \& Pakulak, A. (2004). Evidence for an error monitoring deficit in attention deficit hyperactivity disorder. Journal of Abnormal Child Psychology, 32, 285-293.

Stevens, M., Lammertyn, J., Verbruggen, F., \& Vandierendonck, A. (2006). Tscope: A C library for programming cognitive experiments on the MS Windows platform. Behavior Research Methods, 38, 280-286.

Stuphorn, V., \& Schall, J. D. (2006). Executive control of countermanding saccades by the supplementary eye field. Nature Neuroscience, 9, 925931.

van Boxtel, G. J. M., van der Molen, M. W., \& Jennings, J. R. (2005). Differential involvement of the anterior cingulate cortex in performance monitoring during a stop-signal task. Journal of Psychophysiology, 19, $1-10$.

Verbruggen, F., Liefooghe, B., \& Vandierendonck, A. (2004). The inter- 
action between stop signal inhibition and distractor interference in the flanker and Stroop task. Acta Psychologica, 116, 21-37.

Verbruggen, F., Liefooghe, B., \& Vandierendonck, A. (2005). On the difference between response inhibition and negative priming: Evidence from simple and selective stopping. Psychological Research, 69, 262271.

Verbruggen, F., Liefooghe, B., \& Vandierendonck, A. (2006a). The effect of interference in the early processing stages on response inhibition in the stop signal task. Quarterly Journal of Experimental Psychology, 59, $190-203$.

Verbruggen, F., Liefooghe, B., \& Vandierendonck, A. (2006b). Selective stopping in task switching - The role of response selection and response execution. Experimental Psychology, 53, 48-57.
Verbruggen, F., Notebaert, W., Liefooghe, B., \& Vandierendonck, A. (2006). Stimulus- and response-conflict-induced cognitive control in the flanker task. Psychonomic Bulletin \& Review, 13, 328-333.

Vince, M. A. (1948). The intermittency of control movements and the psychological refractory period. British Journal of Psychology, 38, 149 157.

Williams, B. R., Ponesse, J. S., Schachar, R. J., Logan, G. D., \& Tannock, R. (1999). Development of inhibitory control across the life span. Developmental Psychology, 35, 205-213.

Received July 31, 2006

Revision received May 14, 2007

Accepted June 21, 2007

\section{Instructions to Authors}

For Instructions to Authors, please consult the February 2008 issue of the volume or visit www.apa.org/journals/xhp and click on the "Instructions to authors" link in the Journal Info box on the right. 